\title{
Management of Early Pregnancy Failure and Induced Abortion by Family Medicine Educators
}

\author{
Cara Herbitter, MPH, CPH, Ariana Bennett, MPH, Finn D. Schubert, BA, \\ Ian M. Bennett, MD, PhD, and Marji Gold, MD
}

Background: Reproductive health care, including treatment of early pregnancy failure (EPF) and induced abortion, is an integral part of patient-centered care provided by family physicians, but data suggest that comprehensive training is not widely available to family medicine residents. The purpose of this study was to assess EPF and induced abortion management practices and attitudes of family medicine physician educators throughout the United States and Canada.

Methods: These data were collected as part of a cross-sectional survey conducted by the Council of Academic Family Medicine Educational Research Alliance that was distributed via E-mail to 3152 practicing physician members of Council of Academic Family Medicine organizations.

Results: The vast majority of respondents (88.2\%) had treated EPF, whereas few respondents $(15.3 \%)$ had provided induced medication or aspiration abortions. Of those who had treated EPF, most had offered medication management $(\mathbf{7 2 . 7 \%})$, whereas a minority had provided aspiration management (16.4\%). Almost all respondents (95\%) agreed that EPF management is within the scope of family medicine, and nearly threequarters (73.2\%) agreed that early induced abortion is within the scope of family medicine.

Conclusion: Our findings suggest that family physician educators are more experienced with EPF management than elective abortion. Given the overlap of skills needed for provision of these services, there is the potential to increase the number of family physician faculty members providing induced abortions. (J Am Board Fam Med 2013;26:751-758.)

Keywords: Abortion (Induced), Graduate Medical Education, Miscarriage, Women's Health

Reproductive health care, including treatment of early pregnancy failure (EPF, also referred to as

This article was externally peer reviewed.

Submitted 6 September 2012; revised 5 May 2013; accepted 9 May 2013.

From RHEDI/Reproductive Health Education in Family Medicine, the Department of Family and Social Medicine, Montefiore Medical Center, Bronx, NY (CH, FDS, MG); the Department of Family and Social Medicine, Albert Einstein College of Medicine, Bronx, NY (AB, MG); the Department of Family Medicine and Community Health, University of Pennsylvania Perelman School of Medicine, Philadelphia, PA (IMB).

Funding: Funding for this research was provided by the Institute for Innovative Technology in Medical Education, Lebanon, New Hampshire.

Prior presentation: Data included in this article were presented in poster format at the North American Primary Care Research Group Annual Meeting, New Orleans, Louisiana, December 1-5, 2012; the Davidoff Education Day, Bronx, New York, January 25, 2013; the Society of Teachers of Family Medicine Annual Spring Conference, Baltimore, Maryland, May 1-5, 2013; and the Association of Reproductive Health Professionals Annual Meeting, Denver, Colorado, September 19-21, 2013.

Conflict of interest: none declared. miscarriage) and induced abortion (also referred to as elective abortion), is an integral part of patientcentered care provided by family physicians. In the United States, approximately $12 \%$ of recognized pregnancies end in $\mathrm{EPF}^{1-3}$ while nearly half of pregnancies (49\%) are unintended, and $43 \%$ of these unintended pregnancies end in induced abortion. ${ }^{4}$ Approximately one-quarter of women will experience EPF at some point during their lives. ${ }^{5}$ Given the frequency of these health issues for women of reproductive age, family medicine residents should have direct experience with the management of EPF and undesired pregnancy. Studies to date suggest that such experience and training is not widely available to family medicine residents. In 2008, the Society of Teachers of Family Medi-

Corresponding author: Ariana Bennett, MPH, Department of Family and Social Medicine, Albert Einstein College of Medicine, 3544 Jerome Ave., Bronx, NY 10467 (E-mail: ariana.bennett@einstein.yu.edu). 
cine (STFM) Group on Hospital and Procedural Training issued a consensus statement that by graduation all residents should be exposed to and have an opportunity to train in uterine aspiration. ${ }^{6}$ Although the vast majority of family medicine program directors report that residents receive training in expectant and medication management of EPF, less than two thirds report training in aspiration for EPF management. ${ }^{7}$ Only a small percentage of US family medicine residency programs offer training in induced abortion care as a routine experience $^{8-10}$; however, a growing number of programs have integrated routine training in first-trimester aspiration and/or medication abortion into their standard curriculum. ${ }^{11-16}$ In addition, research at individual medical schools has shown that a majority of students planning to go into family medicine and related fields believe that induced abortion training should be available during residency. ${ }^{17,18}$

To meet the needs of family medicine trainees, an adequate percentage of family physician educators must have experience in the management of EPF and abortion. Limited data exist regarding the provision of EPF management in family medicine. A study of obstetricians/gynecologists (OB/GYNs), midwives, and family doctors found that family doctors were more likely to use and prefer expectant management for EPF when compared with OB/GYNs. In addition, only a small percentage of family doctors had provided aspiration or medication management of EPF in the past 6 months. ${ }^{19,20}$ Data regarding the percentage of family physician educators providing induced abortions and/or their attitudes toward abortion are extremely limited; for the most part they are incomplete or merely suggestive rather than complete and conclusive. Of facilities known to provide induced abortions, 21\% are abortion clinics, $26 \%$ are other clinics, $34 \%$ are hospitals, and 19\% are physicians' offices; however, the specialty of clinical providers at these facilities is unknown. ${ }^{21}$ Of mifepristone (medication) abortions provided by US physicians between November 2000 and May 2007, 11\% were provided by family physicians. ${ }^{22}$ Finally, approximately $21 \%$ of women seeking private-sector family planning care visit a family physician, although evidence suggests substantial limitations in the counseling and services offered in those settings. ${ }^{23-25}$

The purpose of this study was to assess EPF and induced abortion management practices and attitudes of family medicine physician educators throughout the United States and Canada. We hypothesized that despite the technical similarities between the two, a much larger percentage of family medicine physician educators would report provision of care for EPF than for induced abortion.

\section{Methods}

These data were collected as part of a survey conducted by the Council of Academic Family Medicine (CAFM) Educational Research Alliance (CERA). CAFM is a collaboration of the 4 academic family medicine organizations: the Association of Departments of Family Medicine, the Association of Family Medicine Residency Directors, the North American Primary Care Research Group, and STFM. CERA conducts systematic surveys of members of these organizations for research purposes using electronic media in a process that is detailed elsewhere. ${ }^{26}$ The items analyzed for this study were included in a cross-sectional survey distributed by CERA to practicing physician members of STFM, the North American Primary Care Research Group, and the Association of Departments of Family Medicine. The survey was distributed via E-mail to 3152 active unique members of these 3 organizations with valid E-mail addresses. Data collection took place in January and February 2012. The CERA survey was approved by the American Academy of Family Physicians' Institutional Review Board, and data analysis was determined to be exempt from review by the Albert Einstein College of Medicine's Institutional Review Board.

\section{Survey Instrument}

The CERA survey included a total of 23 questions: 4 demographic questions, 10 pertaining to our research, and 9 questions in a separate section on genetic testing designed by another group of researchers. Pilot testing of the survey indicated that the full set of questions took approximately 10 minutes to complete. Our questions assessed respondents' practices and attitudes toward EPF management and abortion care.

\section{Analysis}

Descriptive summaries of survey data included reporting frequencies and percentages for categorical variables. $\chi^{2}$ Goodness of fit tests were used to assess whether respondent demographics and attitudes were significantly related to abortion and 
EPF management practices, as well as to explore the relationship between abortion and EPF management with regard to attitudes and practices. All tests were conducted with $\alpha$ set at 0.05 . Data analysis was conducted using SPSS software version 20.0 (IBM, Chicago, IL).

Because the survey contained 2 subprojects, respondents were allowed to skip questions when completing the survey; denominators were adjusted for each individual question when responses were missing. Because of the controversial status of our topics, to assess for potential response bias we conducted an analysis of the demographic and professional characteristics of responders and nonresponders to questions on the management of EPF and induced abortion. A dummy variable was created to assess missing data for 2 questions that asked respondents to rate their agreement with the following statements: (1) "Treatment of early pregnancy failure (miscarriage) is within the scope of family medicine," and (2) "Early induced abortion provision is within the scope of family medicine." This variable was dichotomized as (1) response of any kind or (2) no response (missing). We conjectured that these 2 attitudinal items were representative questions to assess for overall response bias to our questions and any potential response bias between the abortion and EPF questions. Respondent characteristics were compared for each of these questions using a $\chi^{2}$ analysis of the dummy variable to assess for significant differences between those who responded and those who did not. We then compared characteristics of those who did not respond to the EPF question with those who did not respond to the question about provision of induced abortion. We reasoned that a lack of difference in respondent characteristics between these questions would support the interpretation that there was not significant response bias.

\section{Results}

We achieved an overall response rate of $45 \%$ : 1418 physician members of associated CERA professional organizations completed the survey. Of these, we limited our analysis to the 1198 respondents who identified themselves as US and Canadian faculty/educators and answered at least one of our nondemographic questions. Figure 1 shows a diagram of the application of inclusion criteria. We also assessed for response bias as described in the
Figure 1. Response rate and exclusion criteria.

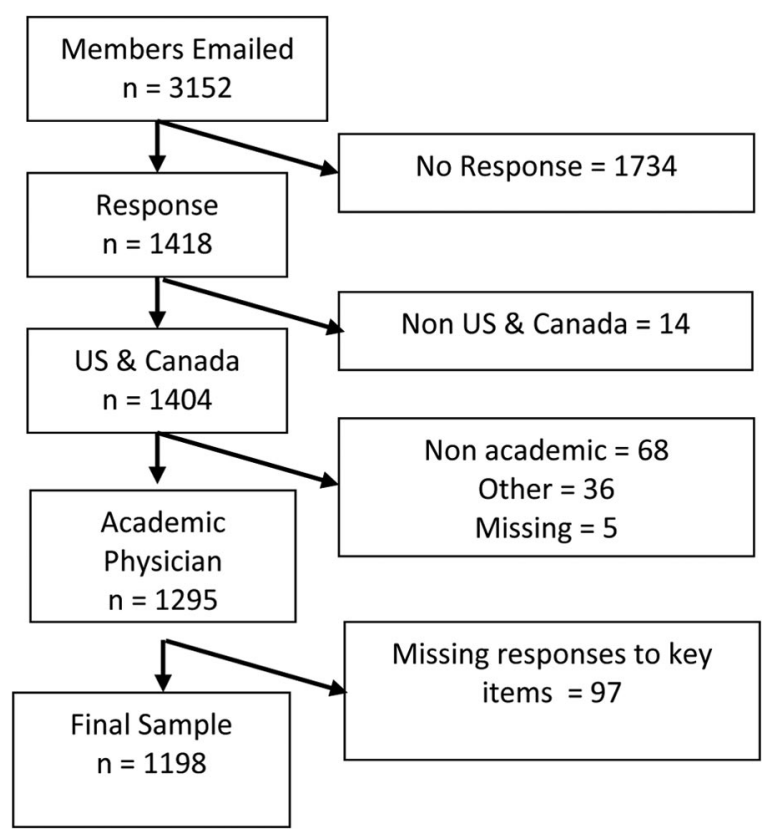

Methods section. Among potential respondents (those who provided any demographic data; $\mathrm{n}=$ 1295), there was no significant difference in the assessed characteristics between responders and nonresponders for each of the 2 representative questions about EPF management and induced abortion. Likewise, there was no statistically significant difference in the characteristics of nonresponders and responders between these 2 questions. These findings do not support the presence of a significant response bias.

The sample was geographically diverse and well distributed, with US physicians reporting residence in the Midwest $(30.1 \%)$, the South $(25.7 \%)$, the Northeast (23.1\%), and the West (21.2\%). A small percentage $(1.6 \%)$ of respondents lived in Canada. Slightly more than half of the respondents were male $(54.8 \%)$, and the majority identified as nonHispanic white (83\%). Detailed demographic information of respondents can be found in Table 1 .

\section{Management of EPF and Induced Abortion}

Respondents were more likely to report ever having provided EPF management than induced abortion care with either medication $(64.5 \%$ vs. $12.5 \%$, respectively) or aspiration (14.3\% vs. $8.7 \%$, respectively; $P<.001$ ). (Note that percentages reported as part of significance testing may vary slightly from those reported elsewhere in our results or tables 
Table 1. Respondent Demographics

\begin{tabular}{lc}
\hline Country $(\mathrm{n}=1198)$ & $19(1.6)$ \\
Canada & $1179(98.4)$ \\
United States & \\
Region $(\mathrm{n}=1177)$ & $272(23.1)$ \\
Northeast & $354(30.1)$ \\
Midwest & $302(25.7)$ \\
South & $249(21.2)$ \\
West & \\
Gender $(\mathrm{n}=1190)$ & $652(54.8)$ \\
Male & $538(45.2)$ \\
Female & \\
Ethnicity (n = 1191) & $989(83.0)$ \\
Non-Hispanic white & $42(3.5)$ \\
Non-Hispanic black & $48(4.0)$ \\
Hispanic & $84(7.1)$ \\
Asian & $28(2.4)$ \\
Other & \\
Age (n = 1192) & \\
$<40$ & $240(20.1)$ \\
$40-49$ & $353(29.6)$ \\
$50-59$ & $440(36.9)$ \\
$\geq 60$ & $159(13.3)$ \\
Half days each week seeing patients in clinic & \\
$\quad(\mathrm{n}=1197)$ & \\
$<3$ & $550(45.9)$ \\
$3-6$ & $576(48.1)$ \\
$\geq 7$ & \\
\hline & \\
&
\end{tabular}

Data are n (\%).

because they are limited to respondents who responded to both questions being tested through crosstabs and $\chi^{2}$ tests.) For the purposes of this study, treatment of EPF was defined as including any of the following: counseling, expectant management, medication management, and/or in-office aspiration procedure. The vast majority of respondents $(88.2 \%)$ reported ever having treated EPF outside of medical school or residency, with counseling (98.2\%) and expectant management (95.9\%) being the most common treatment methods reported. Of these respondents, more than half (56.6\%) had treated EPF in the past year. Of those who have never offered EPF management, about one third $(29.6 \%)$ refer to someone in their practice, and more than half (54.1\%) refer to someone outside their department but within their institution. (See Table 2 for detailed information about EPF management practices. Frequencies for medication and aspiration management of EPF are reported in Table 2 as a percentage of respondents who ever provided EPF.)
Table 2. Early Pregnancy Failure (EPF) Management Practices Among Family Medicine Educator Respondents

Ever treated EPF $(\mathrm{n}=1193)$

$1052(88.2)$

Types of treatment*

Counseling $(n=1043)$

$1024(98.2)$

Expectant management $(\mathrm{n}=1046) \quad 1003(95.9)$

Medication $(n=1045)$

$760(72.7)$

Aspiration $(\mathrm{n}=1042)$

$171(16.4)$

Treated EPF in past year* $(\mathrm{n}=1044) \quad 591(56.6)$

Referral practices ${ }^{\dagger}(\mathrm{n}=135)$

I refer to someone in my practice.

40 (29.6)

I refer to someone outside my department but 73 (54.1) within my institution.

I refer to the emergency department.

I do not refer to anyone in particular.

$17(12.6)$

Data are $\mathrm{n}(\%)$.

${ }^{*}$ Limited to the 1052 respondents who reported ever treating EPF; $\mathrm{n}<1052$ where noted because of missing responses.

${ }^{\dagger}$ Limited to those who reported never treating EPF.

Gender was found to be a significant predictor of having treated EPF, with women slightly more likely than men to report having provided any treatment of EPF $(P<.05)$. Geographic region also was significantly associated with treatment of EPF, with $54.9 \%$ of respondents in the Northeast having treated EPF in the past year, followed by $52 \%$ in the West, $51.6 \%$ in the Midwest, and $40.4 \%$ in the South $(P<.005)$. Age was not found to be a significant predictor.

In contrast to the management of $\mathrm{EPF}$, the vast majority of respondents $(84.7 \%)$ had not provided induced medication or aspiration abortion outside of training. Of those who had ever provided medication abortion outside of training, one third (33.8\%) had provided it in the past year. Of those who have never provided induced medication abortions, three quarters $(78.7 \%)$ offer referrals to other providers for this care. Few respondents (8.6\%) reported having provided induced abortion through aspiration outside of training, and $24 \%$ of those had provided it in the past year. Of those who have never provided induced abortion through aspiration, $81.6 \%$ refer patients for the service. More than one-third of respondents $(36.7 \%)$ who had provided an abortion outside of training had provided both medication and aspiration abortion. (See Table 3 for additional information about induced abortion provision; frequencies for medication and aspiration management of EPF are reported as a percentage of all survey respondents to allow for 
Table 3. Induced Abortion Practices Among Family Medicine Educator Respondents

\begin{tabular}{ll}
\hline Ever provided induced abortion $^{*}$ & \\
Either medication or aspiration $(\mathrm{n}=1174)$ & $180(15.3)$ \\
Medication $(\mathrm{n}=1168)$ & $145(12.4)$ \\
Aspiration $(\mathrm{n}=1157)$ & $100(8.6)$ \\
Provided induced abortion in the past year ${ }^{\dagger}$ & \\
Either medication or aspiration $(\mathrm{n}=180)$ & $53(29.4)$ \\
Medication $(\mathrm{n}=145)$ & $49(33.8)$ \\
Aspiration $(\mathrm{n}=100)$ & $24(24.0)$ \\
\hline
\end{tabular}

Data are n (\%).

*Percentages reported are for all 1198 survey respondents; $\mathrm{n}<$ 1198 where noted because missing responses.

${ }^{\dagger}$ Limited to those who reported ever providing each type of induced abortion.

comparability between medication- and aspirationinduced abortions.)

Nearly one-third of respondents (29.4\%) had received clinical training in induced abortion care during medical school or residency. Respondents who had received clinical training in abortion in medical school or residency were significantly more likely to have provided an abortion outside of training $(P<.001)$.

Although respondents who had offered medication management of EPF were more likely to have provided a medication abortion than those who had not $(P<.001)$, only $18 \%$ of those who had provided medication EPF management had also provided an induced medication abortion. Provision of aspiration for EPF was similarly associated with provision of aspiration abortion $(P<.001)$, and approximately one-third $(31.7 \%)$ of those who offered aspiration for EPF also had provided an induced aspiration abortion.

Neither age nor gender were found to be significant predictors of having provided induced abortion. Abortion provision in the past year varied by geographic region, with those from the West and Northeast being significantly more likely than those from the Midwest or South to report having provided a medication or aspiration abortion in the past year $(7.7 \%, 6.7 \%, 2.6 \%$, and $2.0 \%$, respectively; $P=.001)$.

\section{Attitudes about EPF Management and Abortion}

The results of survey responses regarding attitudes toward EPF management and induced abortion are shown in Table 4. Almost all respondents (95\%) agreed that EPF management is within the scope of
Table 4. Attitudes Regarding Management of Early Pregnancy Failure (EPF) and Induced Abortion Among Family Medicine (FM) Educator Respondents

\begin{tabular}{lc}
\hline EPF management within scope of FM & \\
$\quad(\mathrm{n}=1183)$ & \\
Strongly agree & $712(60.2)$ \\
Agree & $412(34.8)$ \\
Disagree & $37(3.1)$ \\
Strongly disagree & $22(1.9)$ \\
Induced abortion within scope of FM (n = 1154) & \\
$\quad$ Strongly agree & $347(30.1)$ \\
Agree & $498(43.2)$ \\
$\quad \begin{array}{l}\text { Disagree } \\
\text { Strongly disagree }\end{array}$ & $154(13.3)$ \\
Induced abortion legal regulation beliefs & $155(13.4)$ \\
$\quad$ (n = 1147) & \\
It should be legal under any circumstances. & $648(56.5)$ \\
It should be legal only under certain & $412(35.9)$ \\
$\quad$ circumstances. & $87(7.6)$ \\
It should be illegal. & \\
\hline
\end{tabular}

Data are $\mathrm{n}(\%)$.

family medicine, including the majority (76.8\%) of those who had never treated EPF. This did not differ significantly by age, gender, or geographic region.

Nearly three-quarters of respondents (73.2\%) agreed that early induced abortion is within the scope of family medicine, including the majority $(69.2 \%)$ of those who had never provided this care. Nearly all $(94.9 \%)$ of those who had provided an induced abortion believed this service to be within the scope of family medicine. Those who had received clinical training in induced abortion during medical school or residency were significantly more likely to believe that this care is within the scope of family medicine $(87 \%$ vs. $67.4 \%, P<.001)$. In addition, respondents who had provided medication or aspiration treatment for EPF and those who had provided induced abortions were significantly more likely to agree that abortion is within the scope of family medicine (both $P<.001)$.

The vast majority of respondents $(92.4 \%)$ believe that abortion should be legal in all $(56.5 \%)$ or certain $(35.9 \%)$ circumstances, including $91.1 \%$ of respondents who had never provided an abortion. More than three-quarters $(77.3 \%)$ of those who disagreed that induced abortion is within the scope of family medicine reported that they believe that it should be legal in some or all circumstances.

Beliefs about abortion being within the scope of practice of family medicine did not differ signifi- 
cantly by age but were found to vary significantly by region: those from the Northeast and West were more likely to believe that abortion is within the scope of practice than those in the Midwest and South $(81.8 \%, 79.9 \%, 68.2 \%$, and $64.9 \%$, respectively; $P<.001)$. Attitudes about whether abortion should be legal followed a similar pattern by region, but differences were not significant when legality was dichotomized between legal in any/certain circumstances and illegal. However, attitudes about legality did vary significantly by region when the 3 legality response options were left intact: those in the Northeast and West were more likely to believe abortion should be legal in any circumstances than those in the Midwest and South $(67.2 \%, 57.6 \%$, $51.9 \%$, and $48.6 \%$, respectively; $P<.001)$. Similarly, gender was significantly associated with attitudes about abortion: women were significantly more likely to believe that abortion is within the scope of family medicine $(P<.05)$ and that abortion should be legal under any circumstances $(P<$ .001 ), but gender and attitudes about legality did not vary significantly when we dichotomized legality. In addition, age was related to beliefs about legality $(P<.005)$, with respondents younger than the age of 40 significantly more likely to believe that abortion should be illegal.

\section{Discussion}

As anticipated, we found that a much larger proportion of family physician educators are providing EPF management than induced abortions. Consistent with previous studies of family physicians, expectant management is far more commonly used as treatment for EPF than aspiration or medication. Although offering aspiration procedures to manage EPF was associated with offering aspiration-induced abortions, and offering medication management of EPF was associated with offering medication-induced abortions, the majority of respondents offering these methods for EPF management were not offering them as pregnancy termination options. Nearly all respondents believe that EPF management is within the scope of family medicine. Although not as unanimous, the majority of respondents also reported that they believed that induced abortion care is within the scope of family medicine, and the vast majority believe that induced abortion should be legal in at least some circumstances. Providing induced abortion was associated with the belief that this care is within the scope of family medicine, having received clinical abortion training in medical school and/or residency, and practicing in the West and Northeast regions of the United States. For these bivariate analyses, we assessed the relationship between clinical training/attitudes regarding scope of practice and having ever provided induced abortions, whereas for region we assessed its relationship to provision in the past year, since provision that took place more than a year ago might be more likely to include provision in a different region. Attitudes about induced abortion were shown to vary by gender, age, and region. Women and those in the Northeast and West were more likely to believe induced abortion should be legal in all circumstances and that abortion care is within the scope of family medicine, whereas respondents younger than the age of 40 were more likely to believe it should be illegal. Finally, of those who believe that abortion is not within the scope of family medicine, most do believe it should be legal under at least some circumstances.

Given the need for skilled physicians who can provide the full range of services for women seeking EPF management or induced abortion care, it is crucial that family physician educators are themselves providing these services and able to train the next generation of family doctors. Our findings suggest that family physician educators are far more experienced with EPF management than elective abortion. Given the overlap of skills needed for provision of these services, there is the potential to increase the number of family physician faculty members providing induced abortions, particularly in comparison with other primary care specialists who have less procedural training. Previous studies have assessed the barriers to providing induced abortions faced by family physicians and $\mathrm{OB} /$ GYNs, ${ }^{27-31}$ but it would be particularly interesting for future studies to focus on providers who have the skills from their EPF management practices but choose not to provide induced abortions. Although the majority of respondents believed induced abortion care is within the scope of family medicine, there is still greater support for EPF management within family medicine.

Because of the widespread distribution of family physicians, recent findings have highlighted their important role in providing women's health care, while noting a decline in the percentage of family physicians providing these services. ${ }^{32}$ In addition, 
as of $2008,87 \%$ of counties in the United States did not have an abortion provider. ${ }^{21}$ To increase the number of family physicians who can provide early induced abortion care, training during residency seems to be an important factor. Consistent with findings from previous studies, our study shows that experience with abortion training during residency is associated with provision after graduation, once again underlining the importance of increasing the number of faculty willing and able to provide training. In addition, given that attitudes toward abortion are a major barrier to provision and training, it is important to note that the majority of those who state that abortion care is not within the scope of practice of family medicine also believe it should be legal in at least certain circumstances, and more than half $(56.5 \%)$ believe it should be legal in any circumstances. The association between age and abortion attitudes was somewhat surprising, and further research is needed regarding possible attitudinal trends related to the provision of reproductive health care among family physicians and its affect on the future of the specialty. It is interesting that, overall, our respondents demonstrated much broader support for legality than the general American public; a recent Gallup poll showed that more than a quarter $(28 \%)$ of Americans believe abortion should always be legal, half $(52 \%)$ believe it should be legal under certain circumstances, and the remainder (18\%) believe it should never be legal. ${ }^{33}$ Twice as many of our respondents $(56.5 \%)$ believe abortion should be legal under any circumstances, and less than half as many $(7.6 \%)$ believe it should never be legal.

A number of limitations to our study warrant discussion. First, although we have a good overall response rate with a broad geographic distribution and we assessed for response bias based on respondent characteristics, it is still possible that selfselection bias played a role and those who do not believe EPF management and early abortion care are within the scope of family medicine chose not to participate. Because respondents were not forced to answer each question, self-selection bias may have similarly affected particular questions. Second, because this is a cross-sectional study, we cannot assess changes over time, nor can we attribute directionality to any of our associations. Third, it is possible that some respondents who answered affirmatively to having provided medical management for EPF may have been referring to medications other than misoprostol, such as pain medications. Although we do not believe this error is likely to have been widespread, it may account for some small portion of the reported differences between provision of this service and medicationinduced abortion.

Despite these limitations, our findings are an important addition to the family medicine literature, as there are limited published data on family physicians' attitudes toward EPF management and an even greater paucity of studies about attitudes towards and practices of induced abortion among family physicians, including educators, in general. By providing an estimate of the percentage of family physician educators providing medication and aspiration forms of EPF management and those providing medication- and aspiration-induced abortions, as well as describing the attitudes of faculty, we can shape future efforts to increase the number of family medicine educators providing and teaching the broadest range of options for the management of EPF and induced abortions.

The authors thank Dr. Jason Fletcher for his invaluable assistance with data analysis. In addition they thank the staff of the Society of Teachers of Family Medicine, who provided technical support in fielding the survey, collected the results, and provided the study data.

\section{References}

1. Regan L, Braude PR, Trembath PL. Influence of past reproductive performance on risk of spontaneous abortion. BMJ 1989;299:541-5.

2. Everett C. Incidence and outcome of bleeding before the 20th week of pregnancy: prospective study from general practice. BMJ 1997;315:32-4.

3. Hasan R, Baird DD, Herring AH, Olshan AF, Jonsson Funk ML, Hartmann KE. Association between first-trimester vaginal bleeding and miscarriage. Obstet Gynecol 2009;114:860-7.

4. Finer LB, Zolna MR. Unintended pregnancy in the United States: incidence and disparities, 2006. Contraception 2011;84:478-85.

5. Chen BA, Creinin MD. Contemporary management of early pregnancy failure. Clin Obstet Gynecol 2007;50:67-88.

6. Nothnagle M, Sicilia JM, Forman S, et al. Required procedural training in family medicine residency: a consensus statement. Fam Med 2008;40:248-52.

7. Herbitter C, Greenberg M, Fletcher J, Query C, Dalby J, Gold M. Family planning training in U.S. family medicine residencies. Fam Med 2011;43:574-81.

8. Steinauer JE, Depineres T, Robert AM, Westfall J, Darbey $\mathrm{P}$. Training family practice residents in abor- 
tion and other reproductive health care: a nationwide survey. Fam Plann Perspect 1997;29:222-7.

9. Talley PP, Bergus GR. Abortion training in family practice residency programs. Fam Med 1996;28: 245-8.

10. Lesnewski R, Prine L, Gold M. New research abortion training as an integral part of residency training. Fam Med 2003;35:386-7.

11. Bennett IM, Aguirre AC, Burg J, et al. Initiating abortion training in residency programs: issues and obstacles. Fam Med 2006;38330-5.

12. Dehlendorf C, Brahmi D, Engel D, Grumbach K, Joffe C, Gold M. Integrating abortion training into family medicine residency programs. Fam Med 2007;39:337-42.

13. Paul M, Nobel K, Goodman S, Lossy P, Moschella $\mathrm{JE}$, Hammer H. Abortion training in three family medicine programs: resident and patient outcomes. Fam Med 2007;39:184-9.

14. Nothnagle M. Benefits of a learner-centered abortion curriculum for family medicine residents. J Fam Plann Reprod Health Care 2008;34:107-10.

15. Leeman L, Espey E. "You can't do that 'round here": a case study of the introduction of medical abortion care at a University Medical Center. Contraception 2005;71:84-8.

16. Prine L, Lesnewski R, Bregman R. Integrating medical abortion into a residency practice. Fam Med 2003;35:469-71.

17. Espey E, Ogburn T, Leeman L, Nguyen T, Gill G. Abortion education in the medical curriculum: a survey of student attitudes. Contraception 2008;77: 205-8.

18. Shotorbani S, Zimmerman FJ, Bell JF, Ward D, Assefi N. Attitudes and intentions of future health care providers toward abortion provision. Perspect Sex Reprod Health 2004;36:58-63.

19. Dalton VK, Harris LH, Gold KJ, et al. Provider knowledge, attitudes, and treatment preferences for early pregnancy failure. Am J Obstet Gynecol 2010; 202:531-8.

20. Wallace R, Dehlendorf C, Vittinghoff E, Gold KJ, Dalton VK. Early pregnancy failure management among family physicians. Fam Med 2013;45:173-9.

21. Jones RK, Kooistra, K. Abortion incidence and access to services in the United States, 2008. Perspect Sex Reprod Health 2011;43:41-50.
22. Finer L, Wei J. Effect of mifepristone on abortion access in the United States. Obstet Gynecol 2009; 114:623-30.

23. Scholle SH, Chang JC, Harman J, McNeil M. Trends in women's health services by type of physician seen: data from the 1985 and 1997-98 NAMCS. Womens Health Issues 2002;12:165-77.

24. Landry DJ, Wei J, Frost JJ. Public and private providers' involvement in improving their patients' contraceptive use. Contraception 2008;78:42-51.

25. Rubin SE, Fletcher J, Stein T, Segall-Gutierrez P, Gold M. Determinants of intrauterine contraception provision among US family physicians: a national survey of knowledge, attitudes and practice. Contraception 2011;83:472-8.

26. Mainous AG 3rd, Johnson SP, Chirina S, Baker R. Academic family physicians' perception of genetic testing and integration into practice. Fam Med 2013; 45:257-62.

27. Donohoe M. Increase in obstacles to abortion: the American perspective in 2004. J Am Med Womens Assoc 2005;60:16-25.

28. Steinauer J, Landy U, Filippone H, Laube D, Darney PD, Jackson RA. Predictors of abortion provision among practicing obstetrician-gynecologists: a national survey. Am J Obstet Gynecol 2008;198:39.e1-6.

29. Freedman L. Willing and unable: doctors' constraints in abortion care. Nashville, TN: Vanderbilt University Press; 2010.

30. Dehlendorf CE, Grumbach K. Medical liability insurance as a barrier to the provision of abortion services in family medicine. Am J Public Health 2008;98:1770-4.

31. Greenberg M, Herbitter C, Gawinski BA, Fletcher J, Gold M. Barriers and enablers to becoming abortion providers: the reproductive health program. Fam Med 2012;44:493-500.

32. Xierali IM, Puffer JC, Tong STC, Bazemore AW, Green LA. The percentage of family physicians attending to women's gender-specific health needs is declining. J Am Board Fam Med 2012;25:406-7.

33. Saad L. Majority of Americans still support Roe v. Wade decision. Gallup.com, January 22, 2013. Available from: http://www.gallup.com/poll/160058/ majority-americans-support-roe-wade-decision.aspx. Accessed January 30, 2013. 